\section{References and Notes}

(1) K. Kishi and S. Ikeda, Bull. Chem. Soc. Jap., 46, 341 (1973)

(2) K. Kishi and S. Ikeda, Chem. Lett., 245 (1972).

(3) K. Kishi and S. Ikeda, J. Phys. Chem., 73,15 (1969).

(4) Y. Baer, P. F. Heden, J. Hedman, M. Klasson, C. Nordling, and $K$ Siegbahn, Phys. Scr., 1, 55 (1970).

(5) K. Siegbahn, et al., "ESCA; Atomic, Molecular and Solid State Struc- ture Studied by Means of Electron Spectroscopy," Almqvist and Wiksells, Uppsala, 1967

(6) M. Klasson, J. Hedman, A. Berndtsson, R. Nilsson, C. Nordling, and P. Melnik, Phys. Scr., 5,93 (1972)

(7) R. G. Steinhardt, J. Hudis, and M. L. Perlman, Phys. Rev., B, 5, $1016(1972)$.

(8) J. R. Anderson, J. Phys. Chem. Solids, 16, 291 (1960); J. R. Anderson and N. J. Clark, "Proceedings of the 1st Australian Conference on Electrochemistry," Sydney, 1965.

\title{
Optical Spectra and Reactivities of Radical Anions of 4-Nitrobenzyl Compounds Produced by Pulse Radiolysis of Acetonitrile Solutions
}

\author{
H. D. Burrows ${ }^{1}$ and Edward M. Kosower* \\ Department of Chemistry, Tel-Aviv University, Ramat-Aviv, Tel-Aviv, Israel, and Department of Chemistry, State University of New \\ York, Stony Brook, New York, 11790 (Received June 25, 1973)
}

\begin{abstract}
Electronic absorption spectra are reported for transients formed on pulse radiolysis of acetonitrile solutions of aromatic nitrobenzyl compounds and are assigned to the solute radical anions. Decay of the transients is fairly rapid but is markedly slower in the presence of tetraethylammonium formate. It is suggested that the $\cdot \mathrm{CH}_{2} \mathrm{CN}$ radical is responsible for the rapid decay and that formate ion scavenges this species. With 4-nitrobenzyl chloride, the decay of the transient is observed to be second order, in contrast to electrochemical experiments where first-order decay is observed. With 4-nitrobenzyl fluoride or alcohol, decay of the initially formed transient is accompanied by formation of a new species absorbing at longer wavelength. Identification of the 4-nitrobenzyl chloride anion is supported by first-order decay of the species in water with $k=4 \times 10^{3} \mathrm{sec}^{-1}$ (found by Hayon and Madhavan).
\end{abstract}

\section{Introduction}

Radical anions of 4-nitrobenzyl compounds $\mathrm{O}_{2} \mathrm{NC}_{6} \mathrm{H}_{4} \mathrm{CH}_{2} \mathrm{X}$ have been shown by chemical ${ }^{2}$ and electrochemical ${ }^{3-9}$ methods to be unusually reactive. Where the $\mathrm{CH}_{2}-\mathrm{X}$ bond is weak, as in the case of the halides, ${ }^{3-9}$ cyanide, ${ }^{7}$ and thiocyanate, ${ }^{7}$ the predominant fate of the radical anion appears to be the unimolecular decomposition.

$$
\mathrm{O}_{2} \mathrm{NC}_{6} \mathrm{H}_{4} \mathrm{CH}_{2} \mathrm{X}^{-} \longrightarrow \mathrm{O}_{2} \mathrm{NC}_{6} \mathrm{H}_{4} \mathrm{CH}_{2} \cdot+\mathrm{X}^{-}
$$

Electrochemical studies indicate that the rate of this reaction roughly parallels the $\mathrm{CH}_{2}-\mathrm{X}$ bond energies, ${ }^{5-8}$ although the absolute rate constants for this decomposition are not certain. Thus, "single-sweep" cyclic voltammetry of 4-nitrobenzyl chloride in acetonitrile containing $0.1 M$ tetra- $n$-butylammonium perchlorate indicated a rate constant for the decomposition of the radical anion of approximately $50 \mathrm{sec}^{-1}, 7,10$ while other cyclic voltammetric measurements and chronoamperometry suggest the rate constant to be at least $4 \times 10^{3} \mathrm{sec}^{-1} .^{6}$ The failure to obtain consistent results by these procedures may indicate their limitations in studying very fast reactions.

The technique of pulse radiolysis has been shown to be a valuable method for studying short-lived species. Consequently, we have used this procedure to obtain further information on the anion radicals of 4-nitrobenzyl compounds, and attempt to resolve this discrepancy in their decomposition rates.
In addition to providing a suitable solvent for the electrochemical studies, acetonitrile has been shown upon radiolysis to produce a species capable of reducing anthracene to its radical anion in high yield $\left(G=1.55^{11}\right)$ and thus provides a good medium for the pulse radiolysis investigation.

The primary step in the radiolysis of acetonitrile can be written

$$
\mathrm{CH}_{3} \mathrm{CN} \longrightarrow \mathrm{CH}_{3} \mathrm{CN}^{*}+\mathrm{CH}_{3} \mathrm{CN}^{+}+\mathrm{e}^{-}
$$

Pulse radiolysis studies on liquid acetonitrile using naphthalene as an acceptor indicate that the yield of excited states (including excited states formed by solute ion recombination) is low, but detectable $\left(G\left({ }^{3} \mathrm{~N}\right)=0.30\right) .{ }^{11}$ The nature of the reducing species present in the radiolysis of $\mathrm{CH}_{3} \mathrm{CN}$ is not clear at present. An initial report ${ }^{12}$ that a solvated electron, $\lambda_{\max } \sim 700 \mathrm{~nm}, t_{1 / 2} \sim 5 \mu \mathrm{sec}$, was produced has been questioned by Hayon, 11 who was unable to detect any absorption in the range $280-800 \mathrm{~nm}$ with a time resolution of $100 \mathrm{nsec}$.

The oxidizing species formed initially, $\mathrm{CH}_{3} \mathrm{CN} \cdot+$, may be expected to deprotonate to give $\cdot \mathrm{CH}_{2} \mathrm{CN}$ radicals

$$
\mathrm{CH}_{3} \mathrm{CN}^{+}+\mathrm{CH}_{3} \mathrm{CN} \longrightarrow \mathrm{CH}_{2} \mathrm{CN}+\mathrm{CH}_{3} \mathrm{CNH}^{+}
$$

Evidence for the presence of $\cdot \mathrm{CH}_{2} \mathrm{CN}$ radicals comes from steady-state studies, ${ }^{13}$ and also from the observation of a weak absorption at wavelengths shorter than $280 \mathrm{~nm}$ assigned to this species on pulse radiolysis of liquid acetonitrile. ${ }^{11}$ We describe the pulse radiolysis of acetonitrile so- 
lutions of 4-nitrobenzyl compounds, and indicate the reactivities of the resultant species.

\section{Experimental Section}

Materials. 4-Nitrobenzyl fluoride, chloride, and bromide and 4-nitrotoluene were purified as described previously. ${ }^{8}$-Nitrobenzyl iodide was prepared by the method of Finkelstein ${ }^{14}$ and was purified by one recrystallization from ethanol, followed by sublimation (in the absence of light): pale yellow crystals, mp $125.5-127^{\circ}$ (lit..$^{14} 127^{\circ}$ ). 4-Nitrobenzyl acetate was prepared as described by Reid $^{15}$ and was recrystallized twice from aqueous ethanol: white crystals, $\mathrm{mp} 76-77^{\circ}$ (lit. ${ }^{15} 78^{\circ}$ ). 4 -Nitrobenzyl alcohol was obtained by hydrolysis of the acetate ${ }^{16}$ and was recrystallized three times from water: white crystals, $\mathrm{mp}$ 92.5-93.5 (lit. $\left.{ }^{16} 96-97^{\circ}\right)$. Further recrystallization did not affect the melting point. Acetonitrile was purified by two procedures. Merck Uvasol grade was dried by standing over molecular sieves and was redistilled from fresh molecular sieves. Fluka purum grade acetonitrile was purified by the method of O'Donnell, et al. ${ }^{17}$ No difference was found between the results obtained using these different samples.

Tetraethylammonium ferrocyanide was prepared by neutralizing a cold aqueous solution of hexacyanoferric acid $^{18}$ with tetraethylammonium hydroxide. Water was removed under reduced pressure, and the salt crystallized as pale yellow needles. Light was excluded from all manipulations with this compound which was very photosensitive. The salt was added to argon-saturated solutions immediately prior to pulse radiolysis as it was oxidized in the presence of oxygen in acetonitrile. Tetraethylammonium dibenzyl phosphate was prepared by neutralizing hydrogen dibenzyl phosphate ${ }^{19}$ in $60 \%$ aqueous methanol with tetraethylammonium hydroxide. Excess solvent was removed under reduced pressure. The salt was obtained as an oil. Nmr indicated the presence of $20 \%$ water. Tetraethylammonium formate was prepared by neutralizing formic acid with tetraethylammonium hydroxide. Excess water was removed under reduced pressure. The product was obtained as an oil. $\mathrm{Nmr}\left(\mathrm{D}_{2} \mathrm{O}\right)$ indicated peaks at $\delta 8.64$ (s, 1 formate hydrogen), 5.03 (s, water), 3.7-3.2 (q, 8 methylene hydrogens), 1.8-1.25 (three overlapping triplets, 12 methyl hydrogens). The $\mathrm{nmr}$ indicated the presence of $c a .30 \%(\mathrm{w} / \mathrm{w})$ water. The observation of overlapping methyl triplets strongly suggests ion pairing in the salt. Strong ion pairing has been clearly demonstrated by infrared spectroscopy in the related compound, triethylammonium acetate. ${ }^{20}$ On preparing solutions containing tetraethylammonium formate for pulse radiolysis, a small amount of precipitation occurred. Consequently, solutions were filtered immediately before each experiment. This precipitate was not characterized, but it is possibly tetraethylammonium carbonate.

Procedure. Pulse radiolysis experiments were carried out using $0.05-1.5-\mu \mathrm{sec}, 5-\mathrm{MeV}, 200-\mathrm{mA}$ pulses from the electron linear accelerator at the Hebrew University of Jerusalem. The pulses were of up to 2 -krad dose. The irradiation cell was $4 \mathrm{~cm}$ long with multipass optics such that the analyzing light traveled three times through the cell. The details of the experimental setup have been described elsewhere. ${ }^{21}$ Dosimetry was performed using the absorption of the solvated electron in deaerated ethanol at 600 $\mathrm{nm}$, as described by Land, et al. ${ }^{22}$ Extinction coefficients of radical anions were estimated assuming $G=1.55$ for

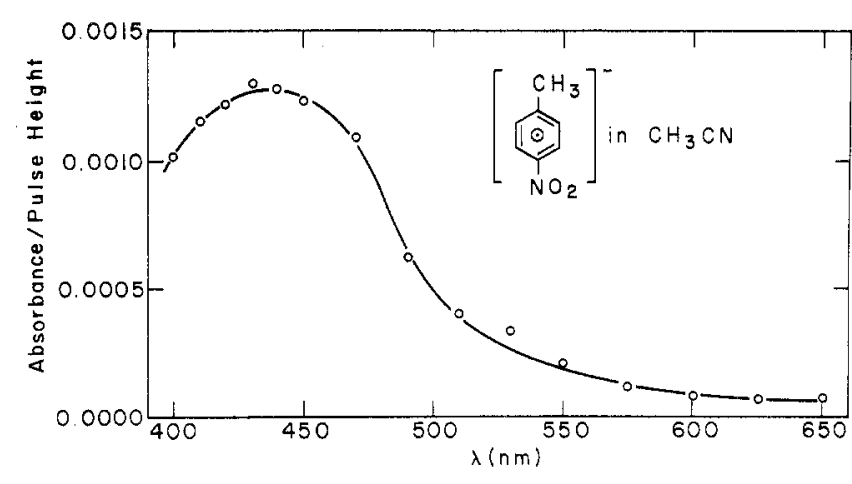

Figure 1. End of pulse spectrum for degassed acetonitrile solution of 4-nitrotoluene.

the reducing species in acetonitrile, with complete scavenging of this species by the solute.

Solutions were degassed by bubbling argon through them prior to radiolysis, and they were protected from photolysis by the monitoring light by insertion of a filter cutting off wavelengths just below the relevant transient absorption.

\section{Results}

Spectra. Pulse radiolysis of a solution of 4-nitrotoluene $\left(6 \times 10^{-3} M\right)$ in acetonitrile resulted in an absorption with $\lambda_{\max } 440( \pm 10) \mathrm{nm}, \epsilon_{\max } \sim 1800 \mathrm{M}^{-1} \mathrm{~cm}^{-1}$ (Figure 1) which was completely formed at the end of a $1.5-\mu \mathrm{sec}$ pulse. A similar absorption was obtained upon pulse radiolysis of 4-nitrotoluene in $10 \%$ acetone-water. This absorption was very similar to the reported spectra of the radical anion of 4-nitrotoluene obtained by electrolysis in dimethylformamide $\left(\lambda_{\max } 460 \mathrm{~nm}\right),{ }^{23}$ by pulse radiolysis in water at $\mathrm{pH} 3\left(\lambda_{\max } 440 \mathrm{~nm}, \epsilon_{\max } 400 M^{-1} \mathrm{~cm}^{-1}\right),{ }^{24}$ and by $\gamma$ radiolysis in 4 -methyltetrahydrofuran at $77 \mathrm{~K}$ $\left(\lambda_{\max } 470 \mathrm{~nm}, \epsilon_{\max } 3500 \mathrm{M}^{-1} \mathrm{~cm}^{-1}\right.$ ), ${ }^{25}$ and is accordingly assigned to this species. The reason for this large differ. ence in extinction coefficients is not at present clear. An earlier report ${ }^{26}$ that the radical anion (obtained by reduction by potassium in tetrahydrofuran) possessed absorption bands at 302,607 , and $875 \mathrm{~nm}$ must be viewed with some caution, as has been previously indicated by Sioda and Kemula. ${ }^{23}$ An identical but more intense absorption was observed on pulse radiolysis of an acetonitrile solution of 4-nitrotoluene in the presence of tetraethylammonium formate $(0.1 M)$. An absorption of similar character, although rather broader and weaker, was observed on pulse radiolysis of a solution of 4-nitrotoluene in the presence of Tris $\left(5 \times 10^{-4} M\right)$ in $95 \%$ acetonitrile-water.

Pulse radiolysis of a solution of 4-nitrobenzyl fluoride (2 $\times 10^{-3} M$ ) in acetonitrile yielded a species absorbing at $490( \pm 10) \mathrm{nm} \epsilon_{\max } \sim 1600^{-1} \mathrm{~cm}^{-1}$ (Figure 2, circles). The species responsible for this absorption is rapidly replaced $\left(t_{1 / 2} \sim 10 \mu \mathrm{sec}\right)$ by a new species absorbing at ca. $625 \mathrm{~nm}$ (Figure 2, triangles). This new species eventually decays, leaving a permanent absorption below $410 \mathrm{~nm}$. The initially formed species is assigned to the radical anion by analogy with 4-nitrotoluene. Assignment of the second $a b$ sorption is more problematical (see Discussion section for a consideration of possible candidates). Similar behavior was observed on pulse radiolysis of solutions of 4-nitrobenzyl fluoride in the presence of tetraethylammonium dibenzyl phosphate $\left(5 \times 10^{-4} M\right)$ tri- $n$-butylamine $(5 \times$ $\left.10^{-4} M\right)$, or tetraethylammonium formate $(0.1 M)$. Pulse radiolysis of a solution of 4-nitrobenzyl fluoride in $95 \%$ ac- 


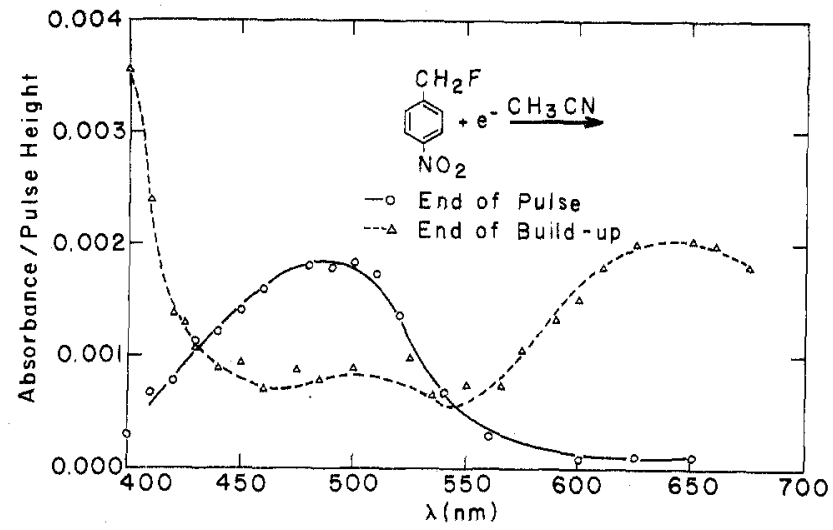

Figure 2. Transients observed upon pulse radiolysis of degassed acetonitrile solution of 4-nitrobenzyl fluoride: - _ - O_- end of pulse; $---\Delta-\cdots$, end of buildup of long wavelength absorption

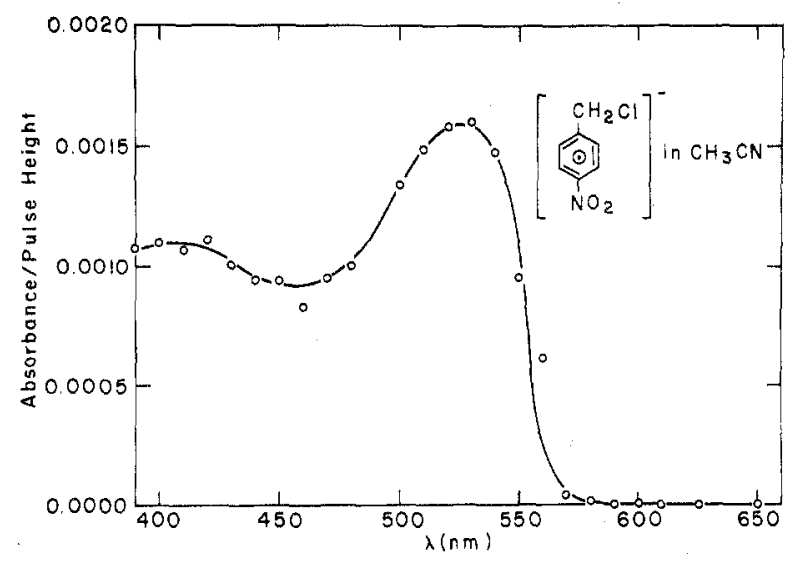

Figure 3. End of pulse spectrum for degassed acetonitrile solution of 4-nitrobenzyl chloride.

etonitrile-water in the presence of tris $\left(2 \times 10^{-4} M\right)$ gave a similar, but rather broader and weaker spectrum.

Tetraethylammonium salts were used because of their solubility in organic media. Ferrocyanide was used as a non-nucleophilic reducing agent, dibenzyl phosphate as a non-nucleophilic proton donor, and formate as a weakly nucleophilic hydrogen atom donor.

Pulse radiolysis of solutions of 4-nitrobenzyl chloride (4 $\left.\times 10^{-3} M\right)$, bromide $\left(2.5 \times 10^{-3} M\right)$, and iodide $(2.5 \times$ $10^{-3} M$ ) gave rather similar behavior for all three halides, with an absorption at $530( \pm 5) \mathrm{nm}, \epsilon_{\max } \sim 1900 \mathrm{M}^{-1}$ $\mathrm{cm}^{-1}$, and a shoulder at $c a .420 \mathrm{~nm}$. The spectrum of 4nitrobenzyl chloride is illustrated in Figure 3. With the chloride and bromide, similar but rather broader and weaker absorptions were observed in the presence of Tris $\left(2 \times 10^{-4} \mathrm{M}\right)$ in $95 \%$ ace tonitrile-water.

Pulse radiolysis of a solution of 4-nitrobenzyl chloride with tetraethylammonium ferrocyanide $\left(5 \times 10^{-3} M\right)$ and water $(2 M)$ gave a similar but broader and weaker absorption which decayed to give a permanent absorption below $460 \mathrm{~nm}$. The absorption was identical in the presence of tetraethylammonium dibenzyl phosphate $(5 \times$ $10^{-4} \mathrm{M}$ ), and similar but more intense in the presence of tetraethylammonium formate $(0.1 M)$.

Pulse radiolysis of a solution of 4-nitrobenzyl acetate ( 2 $\times 10^{-3} M$ ) in acetonitrile yielded an absorption at the end of the pulse at $460( \pm 10) \mathrm{nm}, \epsilon_{\max } \sim 1700 \mathrm{M}^{-1} \mathrm{~cm}^{1}$ (Figure 4). An identical but more intense spectrum was obtained in the presence of tetraethylammonium formate $(0.1 M)$.

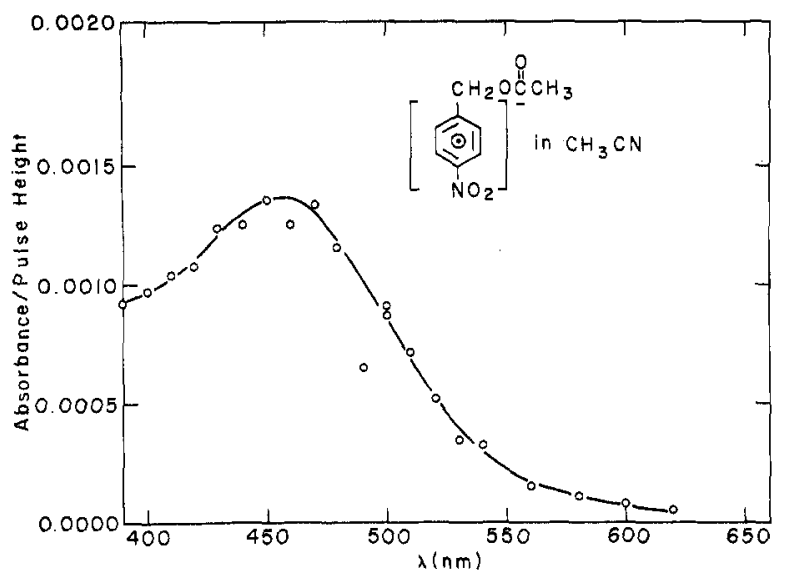

Figure 4. Absorption at end of pulse for degassed acetonitrile solution of 4-nitrobenzyl acetate.

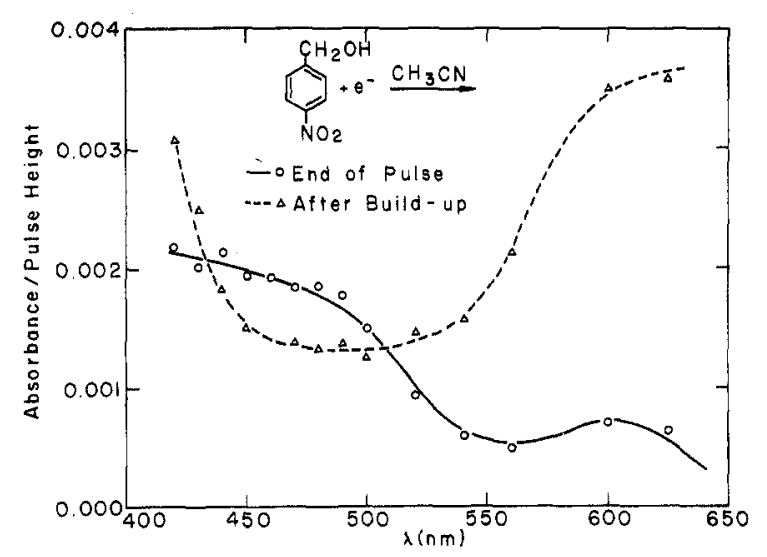

Figure 5. Transients observed upon pulse radiolysis of degassed acetonitrile solution of 4-nitrobenzyl alcohol with tetraethylammonium formate $(0.1 \mathrm{M})$ : end of buildup.

Pulse radiolysis of a solution of 4-nitrobenzyl alcohol (2 $\times 10^{-3} \mathrm{M}$ ) in acetonitrile yielded an absorption at $\mathrm{ca} .450$ $\mathrm{nm}$. Pulse radiolysis in the presence of tetraethylammonium formate $(0.1 M)$ yielded a similar absorption, $\lambda \mathrm{ca}$. $450 \mathrm{~nm}, \epsilon_{450} \sim 1250 \mathrm{M}^{-1} \mathrm{~cm}^{-1}$ which also decayed to give a new species absorbing at $\lambda>625 \mathrm{~nm}$ (Figure 5).

Kinetics. One aim of this work has been to obtain information on the lifetimes of radical anions of 4-nitrobenzyl compounds. However, in the study of the kinetics of the transient absorptions observed on pulse radiolysis of ace. tonitrile solutions of these compounds it became apparent that the species were decaying by a reaction with one of the primary products of the radiolysis of acetonitrile. Thus 4-nitrotoluene, which is known from electrochemical studies to yield a stable radical anion ${ }^{7}$ on pulse radiolysis in acetonitrile yielded a species $\lambda_{\max } 440 \mathrm{~nm}$, which decayed via complex kinetics over a period of hundreds of microseconds. The rate of decay depended upon the pulse size. Similarly, the species observed on pulse radiolysis of 4-nitrobenzyl, chloride, bromide, iodide, acetate, and alcohol decayed fairly rapidly, the decay rate being depen. dent upon the pulse size. Of the products produced on radiolysis of acetonitrile, $\mathrm{CH}_{3} \mathrm{CN} \cdot{ }^{+},{ }^{-} \mathrm{CH}_{2} \mathrm{CN}$, and $\mathrm{H}^{+}$ap. pear the most likely candidates for reacting with the radical anions. Accordingly, compounds were added to trap these species. Tetraethylammonium ferrocyanide was found to have little effect on the decay rate of the species 
obtained from the chloride, although after radiolysis a new absorption was observed below $460 \mathrm{~nm}$, due to the ferricyanide. Thus $\mathrm{CH}_{3} \mathrm{CN}$. + was probably not the reactive species. Similarly, tetraethylammonium dibenzyl phosphate, Tris, or tri-n-butylamine did not markedly affect the decay rate, suggesting protonation was not responsible for the rapid decay. In the radiation chemistry of water, formate ions have been used to trap the oxidizing hydroxyl radical. ${ }^{27}$ With $\cdot \mathrm{CH}_{2} \mathrm{CN}$, formate ion might be expected to transfer a hydrogen atom to yield $\mathrm{CO}_{2}{ }^{--}$, a reducing species. If $\cdot \mathrm{CH}_{2} \mathrm{CN}$ is responsible for the short lifetime of the species obtained on pulse radiolysis, then formate ion may be expected to slow down the decay. Further, as a reducing species is produced, if the absorbing species produced on radiolysis of acetonitrile solutions of 4-nitrobenzyl compounds is the radical anion, or some species derived from it, then the concentration of this species may be expected to be increased on pulse radiolysis in the presence of formate. Pulse radiolysis of acetonitrile solutions of tetraethylammonium formate $(0.1 \mathrm{M})$ revealed only a very weak absorption at wavelengths shorter than $425 \mathrm{~nm}$. Pulse radiolysis of a solution of 4-nitrotoluene in the presence of tetraethylammonium formate $(0.1 \mathrm{M})$ with 2-krad pulses yielded an absorption which was identical in shape, but of about double the intensity of that observed in the absence of the formate. There was a small (less than 10\%) decrease in the absorption at $440 \mathrm{~nm}$, and a corresponding small increase in absorption at $420 \mathrm{~nm}$ over period of $100 \mu \mathrm{sec}$. However, after this time, the absorption was long lived (decayed in greater than $20 \mathrm{msec}$ ). Similar behavior was observed with 4-nitrobenzyl acetate. A likely explanation for this behavior is that the formate ion scavenges most, but not all, of the $\cdot \mathrm{CH}_{2} \mathrm{CN}$ species. Due to problems of solubility, it was not possible to go to higher formate concentrations, however, when smaller pulses (ca. 900 rads) were used there was no decay of the absorption in times less than 20 msec. 4-Nitrobenzyl bromide and iodide appeared to react with the formate in acetonitrile. Pulse radiolysis of 4-nitrobenzyl chloride in the presence of tetraethylammonium formate yielded an $a b$ sorption identical in shape but enhanced in intensity. With large (2-krad) pulses, fairly complex decay kinetics were observed for the first $30 \mu \mathrm{sec}$. After this time, however, the decay followed a second-order rate law to greater than 3 half-lives. As with the 4-nitrotoluene and 4-nitrobenzyl acetate radical anions, the initial decay probably arises from reaction of $\mathrm{CH}_{2} \mathrm{CN}$ with the radical anion. With smaller pulses $(<1 \mathrm{krad})$ only the second-order decay was observed. This showed a slight $(25 \%)$ decrease in the decay rate for a greater than tenfold decrease in pulse size. A mean value of $14.4( \pm 2.3) \times 10^{5} \mathrm{~cm} \mathrm{sec}^{-1}$ was obtained for $k / \epsilon$. Employing the estimated extinction coefficient, the second-order rate constant for the decay is approximately $2.7 \times 10^{9} \mathrm{M}^{-1} \mathrm{sec}^{-1}$. Under the conditions of pulse radiolysis where there are comparatively high $\left(10^{-6}\right.$ to $\left.10^{-7} M\right)$ concentrations of radical anions it would appear that a second-order reaction (possibly radical coupling) is the main fate of this species. This contrasts with the behavior in electrochemical experiments ${ }^{8}$ where, possibly because of the radical concentration, unimolecular decay is the favored reaction.

With 4-nitrobenzyl bromide and iodide it was not possible to scavenge the $\cdot \mathrm{CH}_{2} \mathrm{CN}$ radicals in the same way, as the tetraethylammonium formate very rapidly reacted with the halides in acetonitrile solution, probably via nu- cleophilic substitution, yielding 4-nitrobenzyl formate. However, a lower limit of $70 \mu \mathrm{sec}$ could be set for the lifetimes of the radical anions from the slowest decays.

The decays of the radical anions from 4-nitrobenzyl fluoride and alcohol differed from those of the other derivatives in that new absorptions were observed to grow in on a time-scale similar to the loss of the absorptions assigned to the radical anions. In both these cases the decay appeared to be first-order with rate constants $10^{4}-10^{5} \mathrm{sec}^{-1}$ for $c a .2 \times 10^{-3} M$ solute. With the fluoride, however, the rate of interconversion showed a dependence on 4-nitrobenzyl fluoride concentration. This reaction was not investigated further.

\section{Discussion}

The objective of this study has been to characterize the radical anions of 4-nitrobenzyl compounds, both with regard to their optical spectra and reactivities. It is perhaps surprising that few reports exist on the spectroscopic characterization of these species in view of the large number of studies on reductions of 4-nitrobenzyl compounds in which they are claimed as intermediates. With 4-nitrotoluene, characterization of the radical anion optical spectrum has been achieved by electrochemical, ${ }^{23}$ pulse radiolysis, ${ }^{24}$ and $\gamma$-radiolysis ${ }^{25}$ studies. Our work supports these previous assignments and indicates that in acetonitrile this species has an absorption $\lambda_{\max } 440 \mathrm{~nm}$. This radical anion has also been observed in esr experiments. ${ }^{28,29,31}$ Few other reports of spectra of anion radicals of 4-nitrobenzyl compounds exist in the literature. ${ }^{29-33}$

We tentatively assign the initial spectra observed upon pulse radiolysis of acetonitrile solutions of 4-nitrobenzyl fluoride, 4-nitrobenzyl chloride, 4-nitrobenzyl bromide, 4nitrobenzyl iodide, 4-nitrobenzyl alcohol, and 4-nitrobenzyl acetate to the corresponding radical anions on the basis of the known radiation chemistry of acetonitrile and the behavior observed with 4-nitrotoluene. With the alcohol, acetate, and fluoride similar spectra were observed with a progressive shift of the maxima to lower energies, possibly resulting from a $\sigma-\pi$ interaction similar to the examples reported by Traylor, et $a l .^{34}$ Assignment of the absorptions observed with the chloride, bromide, and iodide is less certain as, although these all possessed a band at longer wavelength than the other derivatives as expected on the basis of $\sigma-\pi$ interactions, the spectra were very similar for these three compounds.

A possible alternative assignment of the absorption which must be considered is the 4-nitrobenzyl radical, formed by dissociative electron capture (4) as has been

$$
\mathrm{RX}+\mathrm{e}^{-} \longrightarrow \mathrm{R} \cdot+\mathrm{X}^{-}
$$

suggested to occur in the reduction of benzyl chloride by hydrated electrons. ${ }^{35}$ This process may be expected to be less important with 4-nitrobenzyl chloride than with benzyl chloride. Further, the decay of the absorbing species is second order. If the 4-nitrobenzyl radical were produced, one might anticipate that hydrogen abstraction from the tetraethylammonium formate would be an important decay pathway for this species. Finally, although in the electrochemical studies there is disagreement over the absolute rate of cleavage of the 4-nitrobenzyl halide radical anions, all workers are agreed that these are actual intermediate species. ${ }^{5,6,8,9}$ Unless, therefore, different factors are important in the electrochemical and radiation chemi- 
cal reductions, we feel that the observed behavior can be best explained by assignment of these absorptions to the corresponding radical anions.

Further evidence in favor of this assignment comes from a study of the pulse radiolysis of 4-nitrobenzyl chloride in aqueous solution (Hayon and Madhavan, unpublished results). A transient is observed both on pulse radiolysis of 4-nitrobenzyl chloride in water in the presence of tertbutyl alcohol and on reduction of 4-nitrobenzyl chloride by $\left(\mathrm{CH}_{3}\right)_{2} \mathrm{COH}$ radical in water. The spectrum of this species is dependent upon the $\mathrm{pH}$, clearly demonstrating an acid-base property. Further, the observed $\mathrm{p} K_{\mathrm{a}}(3.5 \pm$ 0.1 ) is close to that for other substituted nitrobenzene radical anions. ${ }^{24}$ The most reasonable explanation for this behavior is that the transient formed initially upon pulse radiolysis of 4-nitrobenzyl chloride in water is the radical anion, which in acidic solution protonates at the nitro group. If the 4-nitrobenzyl chloride radical anion is sufficiently long-lived in water to permit direct observation by pulse radiolysis $\left(k_{1}=4.1 \pm 0.6 \times 10^{3} \mathrm{sec}^{-1}\right.$ for decay of species in water at $\mathrm{pH} 9.3$ ), it is hardly likely that in acetonitrile the species will decay in a time shorter than that of the first observation $(\sim 1 \mu \mathrm{sec})$. Thus, we feel that the transients observed upon radiolysis of the 4-nitrobenzyl halides in acetonitrile are the radical anions.

Analysis of the decay kinetics of the radical anions, under conditions in which the species did not react with solvent-derived radicals (i.e., using low doses, with $0.1 \mathrm{M}$ tetraethylammonium formate) indicated that while the radical anions of 4-nitrotoluene and 4-nitrobenzyl acetate were long-lived (lifetime greater than $20 \mathrm{msec}$ ) the species from the 4-nitrobenzyl chloride decayed by a second-order process with rate constant $c a .3 \times 10^{9} M^{-1} \mathrm{sec}^{-1}$. This reaction may be either dimerization of disproportionation of the radical anion and is in marked contrast to the electrochemical experiments where, possibly as a result of the lower radical concentrations, unimolecular decay predominates. With 4-nitrobenzyl bromide and iodide, it was only possible to set a lower limit of $c a .70 \mu$ sec for the lifetime of these radical anions.

A plausible scheme for the second-order disappearance of the 4-nitrobenzyl chloride radical anion can be formulated on the following principles: (1) $\pi$ radicals can interact to form dimer complexes, which we have termed $\pi$ mers; ${ }^{36}$ (2) reversible electron transfer, forming 4-nitrobenzyl chloride and 4-nitrobenzyl chloride dianion the dianion would surely lose chloride ion extremely quickly); or (3) simultaneous loss of two chloride ions with formation of a covalent bond between the two rings in the $\pi$ mer. Charged $\pi$ radicals are well known to form $\pi$-mers, e.g., dimethylbipyridylium cation radical ${ }^{37}$ and tetracyanoquinodimethane radical anion ${ }^{38}$ (reactions $5-7$ ).

4-Nitrobenzyl fluoride and 4-nitrobenzyl alcohol showed rather different behavior from the other compounds investigated. The radical anions were observed to convert to a new species possessing an absorption at ca. $625 \mathrm{~nm}$. Furthermore, in the case of the 4-nitrobenzyl fluoride the rate of this interconversion was found to depend upon the solute concentration. Hawley and coworkers ${ }^{5}$ observed similar electronic spectra on electroreduction of $4,4^{\prime}$-dinitrobibenzyl or 4-nitrobenzyl chloride in acetonitrile, suggesting that an anionic species derived from dinitrobibenzyl may be responsible for the absorptions. This assignment would explain the observed dependence of the interconversion on the solute concentration in the case of 4-nitrobenzyl fluo-

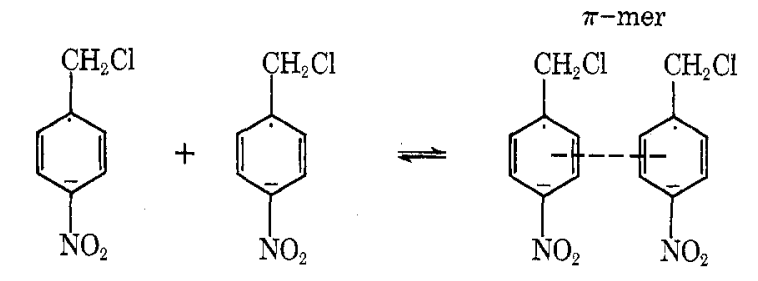<smiles>O=[N+]([O-])c1ccc(CCl)cc1</smiles><smiles>C=C1C=CC(CC)C=C1[N+](=O)[O-]</smiles><smiles>O=[N+]([O-])c1ccc(CCc2ccc([N+](=O)[O-])cc2)cc1</smiles>

ride. However, a firm proposal for the structure of the $625-\mathrm{nm}$ absorbing material requires further work.

Acknowledgments. We thank Professor G. Czapski and the linac group at the Hebrew University of Jerusalem for access to their facilities, and we are particularly grateful to Mr. J. Ogdan for maintenance of the accelerator and electronic equipment. Professor E. Hayon and V. Madhavan (U. S. Army Natick Laboratories) were kind enough to send us their results on 4-nitrobenzyl chloride. We are grateful to the Petroleum Research Fund of the American Chemical Society for financial support.

\section{References and Notes}

(1) Universidade de Coimbra, Laboratório Qúimico da Faculdade de Ciências, Coimbra, Portugal.

(2) L Weisler and $R$ W Helmkamp, \& Amer Chem. Soc., 67, 1167 (1945); H. B. Hass and M. L. Bender, ibid., 71, 1767, 3482 (1949) R. C. Kerber, G. W. Urry, and N. Kornblum, ibid., 87, 4520 (1965) R. C. Kerber, G. W. Urry, and N. Kornblum, ibid., 87, $4520(1965)$
N. Kornblum. R. E. Michel, and R. C. Kerber, ibid., 88, 5660 (1966); G. A. Russell and W. C. Danen, ibid., 88, 5663 (1966).

(3) G. Klopman, Helv. Chim. Acta, 44, 1908 (1961)

(4) J. Grimshaw and J. S. Ramsay, J. Chem. Soc. B, 60 (1968)

(5) J. G. Lawless, D. E. Bartak, and M. D. Hawley, J. Amer. Chem Soc., 91, 7121 (1969)

(6) D. E. Bartak and M. D. Hawley, J. Amer. Chem. Soc., 94, 640 (1972).

(7) M. Mohammad, J. Hajdu, and E. M. Kosower, J. Amer. Chem. Soc., 93, $1792(1971)$.

(8) M. Mohammad and E. M. Kosower, J. Amer. Chem. Soc., 93, 2713 (1971).

(9) P. Peterson, A. K. Carpenter, and R. F. Nelson, J. Electroanal Chem. Interfacial Electrochem., 27, 1 (1970).

(10) In a preliminary report ${ }^{7}$ this value was given as approximately 10-20 sec-1 . More detailed electrochemical analysis gives a value of $50 \mathrm{sec}^{-1} ; \mathrm{M}$. Mohammad, unpublished work.

(11) E Hayon I Chem. Phys, 53, 2353 (1970).

(12) A. Singh, H. D. Gesser, and A. R. Scott, Chem. Phys. Lett., 2, 271 (1968).

13) D. Bradley and J. Wilkinson, J. Chem. Soc. A, 531 (1967).

(14) H. Finkelstein, Chem Ber, 43,1531 (1910); Chem. Abstr., 2441 H. Finkel

(15) E. E. Reid, J. Amer, Chem. Soc., 39, 124 (1917)

(16) W. W. Hartman and E. J. Rahrs, "Organic Syntheses," Coll. Vol. 
III, Wiley, New York, N. Y., 1955, p 652

(17) J. F. O'Donnell, J. T. Ayres, and C. K. Mann, Anal. Chem., 37, $1161(1965)$.

(18) Prepared according to $\mathrm{H}$. Lux, "Handbook of Preparative Inorganic Chemistry," 2nd ed, G. Brauer, Ed. Academic Press, New York, N. Chemistry," 2nd

(19) F. R. Atherton, H. T. Howard, and A. R. Todd, J. Chem. Soc., 1111 (1948)

(20) G. M. Barrow and E. A. Yerger, J. Amer. Chem. Soc., 76, 5211 (1954).

(21) Internal Report of the Accelerator Laboratory, Hebrew University, Jerusalem, Israel; N. N. Lichtin, J. Ogdan, and G. Stein, Biochim. Biophys. Acta, 263, 14 (1972).

(22) E. J. Land, J. T. Richards, and J. K. Thomas, J. Phys. Chem., 76, 3805 (1972)

(23) R. E. Sioda and W. Kemula, J. Electroanal. Chem. Interfacial Electrochem., 31, $113(1971)$.

(24) W. Gruenbein, A. Fojtik, and A. Henglein, Z. Naturforsch, 24b, 1336 (1969)

(25) T. Shida and S. I wata, J. Phys. Chem., 75, 2591 (1971).

(26) A. Ishitanl, K. Kuwata, H. Tsubomura, and S. Nagakura, Bull. Chem. Soc. Jap., 36, 1357, (1973).
(27) See, for example, E. J. Land and A. J. Swallow, Biochim. Biophys. Acta, 162, 327 (1968)

(28) A. H. Maki and D. H. Geske, J. Amer. Chem. Soc., 83, 1852 (1961).

(29) P. L. Kolker and W. A. Waters, J Chem. Soc, 1136 (1964).

(30) W. M. Gulick and D. H. Geske, J. Amer. Chem. Soc., 88, 2928 W. M. Gulick and D. H. Geske, J. Amer. Chem. Soc., 88, 2928 (1966).

(31) P. B. Ayscough, F. P. Sargent, and R. Wilson, J. Chem. Soc., 5418 (1963)

(32) G. A. Russell and W. C. Danen, J. Amer. Chem. Soc., 90, 347 (1968).

(33) W. E. Griffiths, G. F. Longster, J. Myatt, and P. F. Todd, J. Chem. Soc. $B, 1130(1966)$.

(34) W. Hanstein, H. J. Berwin, and T. G. Traylor, J. Amer. Chem. Soc., $92,829(1970)$.

(35) J. P. Mittal and E. Hayon, Nature (London), Phys. Sci., 240, 20 (1972), and references therein.

(36) E. M. Kosower and J. Hajdu, J. Amer. Chem. Soc., 93, 2534 (1971).

(37) E. M. Kosower and J. L. Cotter, J. Amer. Chem. Soc., 86, 5524 (1964)

(38) R. H. Boyd and W. D. Phillips, J. Chem. Phys., 43, 2927 (1965).

\title{
Electron Paramagnetic Resonance Study of Radicals Formed from Allyl Compounds ${ }^{1}$
}

\author{
P. Smith, ${ }^{*}$ R. A. Kaba, ${ }^{2}$ and P. B. Wood \\ Paul M. Gross Chemical Laboratory, Department of Chemistry, Duke University, Durham, North Carolina 27706 \\ (Received August 27, 1973)
}

\begin{abstract}
Using the $\mathrm{TiCl}_{3}-\mathrm{H}_{2} \mathrm{O}_{2}$ radical-generating method within a continuous-flow system at ca. $25^{\circ}$, we have carried out a comprehensive epr study of the radicals formed from $\mathrm{CH}_{2}=\mathrm{C}\left(\mathrm{CH}_{3}\right) \mathrm{CH}_{2} \mathrm{OH}$ and 14 allyl compounds, viz., $\left(\mathrm{CH}_{2}=\mathrm{CHCH}_{2}\right)_{2} \mathrm{O}$ and $\mathrm{CH}_{2}=\mathrm{CHCH}_{2} \mathrm{X}$ with $-\mathrm{X}$ equal to $-\mathrm{OH},-\mathrm{OOCH},-\mathrm{OOCCH}_{3}$, $-\mathrm{OOCCH}_{2} \mathrm{CH}_{3},-\mathrm{OOCCH}_{2} \mathrm{CH}_{2} \mathrm{CH}_{3},-\mathrm{OOCC}_{6} \mathrm{H}_{5},-\mathrm{CN},-\mathrm{NH}_{2},-\mathrm{NHCONH}_{2},-\mathrm{COOH},-\mathrm{OCH}_{2} \mathrm{CH}_{2} \mathrm{OH}$, $-\mathrm{OCH}_{2} \mathrm{CH}_{3}$, and $-\mathrm{OCH}_{2} \mathrm{CHCH}_{2} \mathrm{O}$. Generally, water was the reaction solvent. However, the aromatic compound was not sufficiently soluble in this medium and so was run in water mixed with acetone. Each $\mathrm{CH}_{2}=\mathrm{CHCH}_{2} \mathrm{X}$ compound gave only the $\mathrm{HOCH}_{2} \mathrm{CHCH}_{2} \mathrm{X}, 1(-\mathrm{X})$, and $\cdot \mathrm{CH}_{2} \mathrm{CH}(\mathrm{OH}) \mathrm{CH}_{2} \mathrm{X}, 2(-\mathrm{X})$, radicals, except that $\mathrm{CH}_{2}=\mathrm{CHCH}_{2} \mathrm{OH}$ also yielded $\mathrm{CH}_{2} \cdots \mathrm{CH} \cdots \mathrm{CHOH}$. The $\mathrm{CH}_{2}=\mathrm{C}\left(\mathrm{CH}_{3}\right) \mathrm{CH}_{2} \mathrm{OH}$ and $\left(\mathrm{CH}_{2}=\mathrm{CHCH}_{2}\right)_{2} \mathrm{O}$ each gave only one radical, of structure analogous to $1(-\mathrm{X})$, although the spectrum formed from the ether was broadlined and might contain other radicals. To help characterize some of the $1(-X)$ and $2(-X)$ radicals, we have carried out a similar investigation where we replaced the $\mathrm{H}_{2} \mathrm{O}_{2}$ in the $\mathrm{TiCl}_{3}-\mathrm{H}_{2} \mathrm{O}_{2}$ system with $\mathrm{NH}_{2} \mathrm{OH}$, five $\mathrm{CH}_{2}=\mathrm{CHCH}_{2} \mathrm{X}$ compounds being so examined, viz., with $-\mathrm{X}$ equal to $-\mathrm{OH},-\mathrm{OOCH},-\mathrm{OOCCH} \mathrm{CH}_{2} \mathrm{CH}_{3},-\mathrm{NH}_{2}$, and $-\mathrm{OCH}_{2} \mathrm{CHCH}_{2} \mathrm{O}$. Each of these compounds gave only the $\mathrm{H}_{2} \mathrm{NCH}_{2} \mathrm{CHCH}_{2} \mathrm{X}$ radical, except that $\mathrm{CH}_{2}=\mathrm{CHCH}_{2} \mathrm{OH}$, when run at high enough concentrations, also produced a signal assignable to a polymeric radical.
\end{abstract}

\section{Introduction}

The reaction between titanous chloride and hydrogen peroxide in the presence of a reactive organic substrate within an aqueous continuous-flow system is the basis of a well known method of generating transient free radicals in electron paramagnetic resonance, epr, spectroscopic investigations. ${ }^{3,4}$ In an earlier paper, ${ }^{5}$ we reported the results of an epr spectroscopic study of the radicals observed to be formed from allyl alchohol, $\mathrm{CH}_{2}=\mathrm{CHCH}_{2} \mathrm{OH}$ or $\mathrm{AOH}$, as substrate with the use of this method. We found this substrate to yield the two conceivable addition radicals $\mathrm{HO}$ $\mathrm{CH}_{2} \mathrm{CHCH} \mathrm{CH}_{2} \mathrm{OH}$, and $\cdot \mathrm{CH}_{2} \mathrm{CH}(\mathrm{OH}) \mathrm{CH}_{2} \mathrm{OH}$, 2, as the major products. Also observed was the allylic radical - $\mathrm{CH}_{2} \mathrm{CH}=\mathrm{CHOH} \leftrightarrow \mathrm{CH}_{2}=\mathrm{CHCHOH}, 3$, and, when the allyl alcohol concentration was sufficiently high, there was noticed a signal attributable to a polymeric addition radi- cal. On the other hand, when the photodecomposition of hydrogen peroxide is employed as the radical-generating reaction, only radical 3 is observed ${ }^{6,7}$

The present paper represents an extension of our previous investigation to the study of other allyl compounds with the use of the $\mathrm{TiCl}_{3}-\mathrm{H}_{2} \mathrm{O}_{2}$ method. In general, our results with these allyl compounds are similar to those of our earlier work. ${ }^{5}$ However, for no allyl compound except allyl alcohol did we readily observe a signal attributable to an allylic radical and, consequently, we made no attempt to pursue this aspect. Also, for each allyl compound studied, the concentration was low enough that we did not observe a polymeric radical spectrum. ${ }^{5}$ The resolution we could obtain under optimum conditions proved to be much better than before, thus allowing, for example, a more complete characterization of radical 1 and the observation of an $\epsilon$-proton coupling in several ether radicals. 